\title{
Subclinical Hypothyroidism as a New Therapeutic Target for Patients With Heart Failure With Preserved Ejection Fraction
}

\author{
Yoshiharu Kinugasa, MD; Kazuhiro Yamamoto, MD
}

$\mathbf{S}$ ubclinical hypothyroidism ( $\mathrm{SCH})$ is defined as an elevated level of thyroid-stimulating hormone (TSH) with a normal thyroxine (T4) level. The prevalence of SCH has been previously reported as between $7 \%$ and $10 \%,{ }^{1}$ and it is particularly common in older women. The cardiovascular system is a specific target of thyroid hormone. $\mathrm{SCH}$ is associated with hypercholesterolemia, left ventricular diastolic dysfunction, endothelial dysfunction, and increased serum C-re- active protein (CRP) levels. ${ }^{2}$ A recent meta-analysis revealed that $\mathrm{SCH}$ is associated with increased risk of coronary artery disease events and mortality. ${ }^{3}$ In addition, it is also associated with the development of heart failure (HF) in patients with and without underlying heart disease. ${ }^{4,5}$ The Health Aging and Body Composition population-based study showed that patients (aged 70-79 years) with TSH levels $\geq 7 \mathrm{mU} / \mathrm{L}$, who were monitored for 4 years, had a higher risk of HF events than

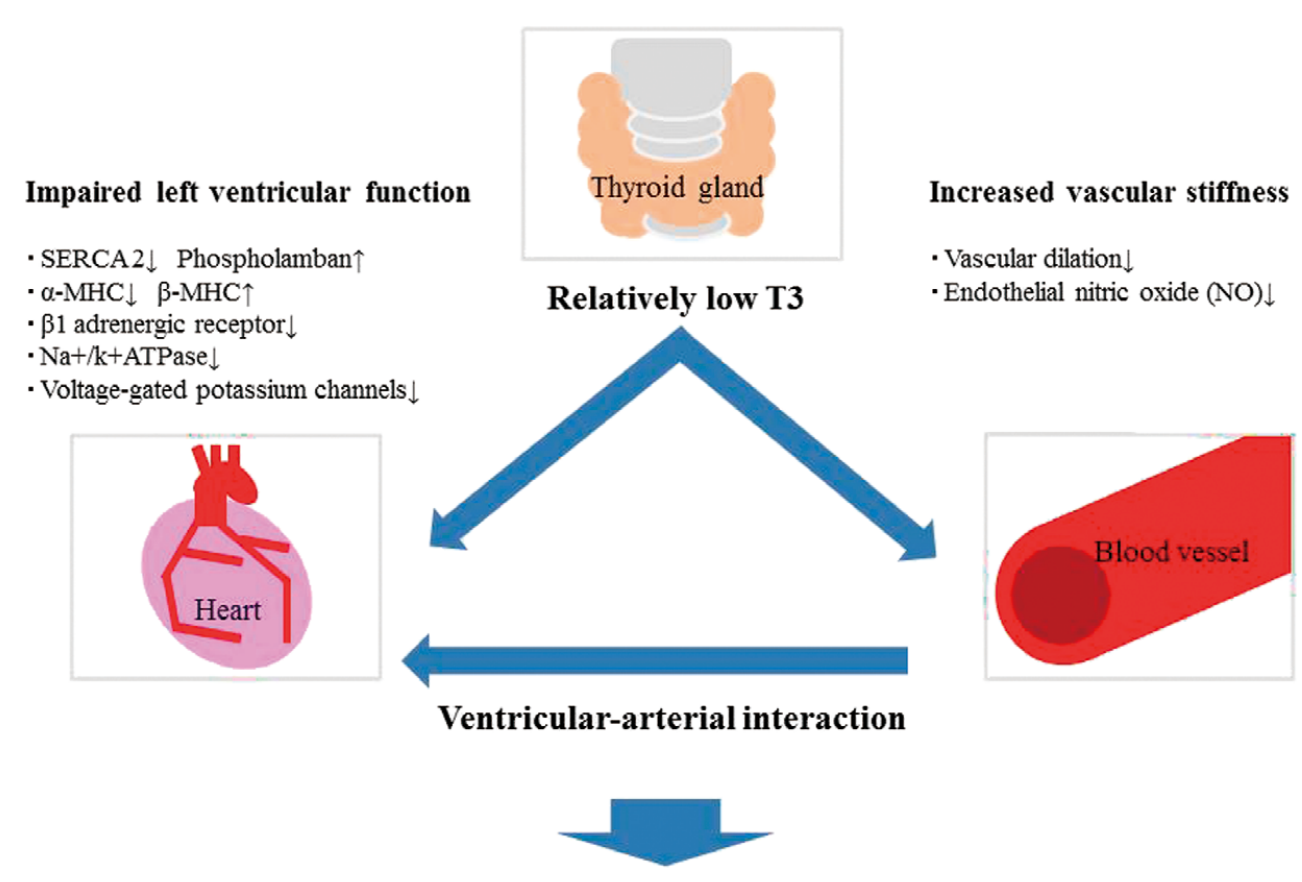

Increased risk of the development of heart failure

Figure. Proposed mechanism of the development of heart failure in patients with subclinical hypothyroidism. $a-\mathrm{MHC}$; $a$-myosin heavy chain; SERCA 2; sarcoplasmic calcium ATPase activity.

The opinions expressed in this article are not necessarily those of the editors or of the Japanese Circulation Society.

Received April 10, 2014; accepted April 10, 2014; released online April 24, 2014

Division of Cardiovascular Medicine, Endocrinology and Metabolism, Department of Molecular Medicine and Therapeutics, Faculty of Medicine, Tottori University, Yonago, Japan

Mailing address: Kazuhiro Yamamoto, MD, Division of Cardiovascular Medicine, Endocrinology and Metabolism, Department of Molecular Medicine and Therapeutics, Faculty of Medicine, Tottori University, 86 Nishi-cho, Yonago 683-8503, Japan. E-mail: ykazuhiro@med. tottori-u.ac.jp

ISSN-1346-9843 doi:10.1253/circj.CJ-14-0436

All rights are reserved to the Japanese Circulation Society. For permissions, please e-mail: cj@j-circ.or.jp 
euthyroid patients. ${ }^{4,5}$ In the multivariate analysis, the hazard ratio was 2.58 (95\% confidence interval [CI], 1.19-5.60) for patients with a TSH level between 7.0 and $9.9 \mathrm{mU} / \mathrm{L}$ and 3.26 (95\% CI 1.37-7.77) for patients with a TSH level $\geq 10.0 \mathrm{mU} / \mathrm{L}$ or greater. ${ }^{3,4}$ Thus, $\mathrm{SCH}$ is a critical risk factor for cardiovascular diseases.

\section{Article p 1494}

In this issue of the Journal, Masaki et al firstly report a relationship between thyroid hormone levels and arterial wall stiffness as assessed by the cardio-ankle vascular index (CAVI) in patients with $\mathrm{SCH} .{ }^{6} \mathrm{CAVI}$ was significantly related to free triiodothyronine (FT3) concentrations, CRP, log N-terminal prohormone of brain natriuretic peptide (NT-proBNP), and echocardiographic indices of left ventricular diastolic function. ${ }^{6}$ FT3 directly affects the vascular smooth muscle cells and enhances the production of endothelial nitric oxide, which promotes relaxation of the peripheral vasculature. ${ }^{1,4}$ Furthermore, SCH patients had significantly higher CRP levels than those with normal thyroid function, indicating that inflammation might also play an important role in the acceleration of atherosclerosis in patients with $\mathrm{SCH} .^{2}$ These findings may well explain the relation between CAVI and thyroid hormone levels.

Masaki et al also show that SCH patients had impaired left ventricular diastolic function and elevated NT-pro BNP levels compared with euthyroid patients. ${ }^{6}$ The impaired left ventricular diastolic function is a critical pathophysiological mechanism of $\mathrm{HF}$ with preserved ejection fraction $(\mathrm{HFpEF}) .{ }^{7} \mathrm{SCH}$ is common in older people, and HFpEF is also a common phenotype of the elderly HF population. ${ }^{8}$ Previous study has shown that $22 \%$ of patients with HFpEF had abnormal thyroid function, and increased BNP and severe diastolic dysfunction were independently associated with lower T3 levels. ${ }^{9}$ A low T3 level reduces sarcoplasmic calcium ATPase activity, with consequent impairment of left ventricular diastolic function. ${ }^{1,4,10}$ Thus, thyroid dysfunction is a likely potential cause of $\mathrm{HFpEF}$.

Importantly, increased CAVI was associated with impaired left ventricular diastolic function in patients with $\mathrm{SCH} .{ }^{6}$ Takeda et $\mathrm{al}^{11}$ recently reported changes in vascular stiffness and the development of left ventricular hypertrophy after undergoing endovascular aortic repair (EVAR). They evaluated patients undergoing EVAR for abdominal and/or thoracic aneurysm with preserved ejection fraction, and showed that the brachialankle pulse wave velocity (baPWV), left ventricular mass index (LVMI), and left atrial volume index as markers of comprehensive diastolic dysfunction were significantly elevated after EVAR compared with baseline data. The changes in baPWV correlated with those in LVMI and were associated with decreased exercise tolerance, indicating that EVAR increased vascular stiffness and led to left ventricular hypertrophy and diastolic dysfunction. Kass proposed t issue hat vascular stiffening was accompanied by changes in left ventricular chamber stiffness, and that ventricular-arterial interaction might be an important pathophysiological mechanism of the develop- ment of HFpEF. ${ }^{7}$ Therefore, in addition to the direct impairment of diastolic function, ventricular-arterial uncoupling may contribute to the development of HFpEF in patients with $\mathrm{SCH}$ (Figure).

Small studies have shown that T4 replacement therapy for 6 months improved systolic and diastolic function in patients with SCH. ${ }^{10}$ In addition, it also reduced systemic vascular resistance, which confirms a direct vasodilatory effect of thyroid hormone. The Cardiovascular Health Study showed that the risk of $\mathrm{HF}$ was significantly lower in T4-treated patients than in untreated patients. ${ }^{12}$ Furthermore, patients with TSH $>10 \mathrm{mU} / \mathrm{L}$ had an increased risk of HF during periods of T4 withdrawal than during its use. ${ }^{12}$ These findings indicate that T4 therapy may reduce the risk of HF in patients with $\mathrm{SCH}$.

Thyroid dysfunction is a reversible cause of HF, and T4 replacement therapy has beneficial hemodynamic effects in patients with SCH. Although the effect of such treatment on mortality remains unclear, thyroid function tests should be evaluated in any patients with newly diagnosed HF, especially $\mathrm{HFpEF}$, and further investigations are necessary to evaluate the prognostic significance of $\mathrm{T} 4$ replacement therapy in $\mathrm{HF}$ patients with SCH.

\section{References}

1. Klein I, Danzi S. Thyroid disease and the heart. Circulation 2007; 116: $1725-1735$.

2. Tseng FY, Lin WY, Lin CC, Lee LT, Li TC, Sung PK, et al. Subclinical hypothyroidism is associated with increased risk for all-cause and cardiovascular mortality in adults. J Am Coll Cardiol 2012; 60: $730-737$.

3. Rodondi N, den Elzen WP, Bauer DC, Cappola AR, Razvi S, Walsh JP, et al. Subclinical hypothyroidism and the risk of coronary heart disease and mortality. JAMA 2010; 304: 1365-1374.

4. Biondi B. Heart failure and thyroid dysfunction. Eur J Endocrinol 2012; 167: 609-618.

5. Rodondi N, Newman AB, Vittinghoff E, de Rekeneire N, Satterfield $\mathrm{S}$, Harris TB, et al. Subclinical hypothyroidism and the risk of heart failure, other cardiovascular events, and death. Arch Intern Med 2005; 165: $2460-2466$.

6. Masaki M, Komamura K, Goda A, Hirotani S, Otsuka M, Nakabo A, et al. Elevated arterial stiffness and diastolic dysfunction in subclinical hypothyroidism. Circ J 2014; 78: 1494-1500.

7. Kass D. Ventricular arterial stiffening integrating the pathophysiology. Hypertension 2005; 46: 185-193.

8. Kinugasa Y, Kato M, Sugihara S, Hirai M, Yamada K, Yanagihara K, et al. Geriatric nutritional risk index predicts functional dependency and mortality in patients with heart failure with preserved ejection fraction. Circ J 2013; 77: 705-711.

9. Selvaraj S, Klein I, Danzi S, Akhter N, Bonow RO, Shah SJ. Association of serum triiodothyronine with B-type natriuretic peptide and severe left ventricular diastolic dysfunction in heart failure with preserved ejection fraction. Am J Cardiol 2012; 110: 234-239.

10. Biondi B, Fazio S, Antonio P, Carella C, Panza N, Cittadini A, et al. Left ventricular diastolic dysfunction in patients with subclinical hypothyroidism. J Clin Endocrinol Metab 84: 2064-2067, 1999.

11. Takeda Y, Sakata Y, Ohtani T, Tamaki S, Omori Y, Tsukamoto Y, et al. Endovascular aortic repair increase vascular stiffness and alters cardiac structure and function. Circ J 2014; 78: 322-328.

12. Rodondi N, Bauer DC, Cappola AR, Cornuz J, Robbins J, Fried LP, et al. Subclinical thyroid dysfunction, cardiac function, and the risk of heart failure: The Cardiovascular Health study. J Am Coll Cardiol 2008; 52: 1152-1159. 